\begin{tabular}{|l|l|l||}
\hline \multicolumn{2}{|c|}{ PublisherInfo } \\
\hline \hline PublisherName & $:$ & BioMed Central \\
\hline \hline PublisherLocation & $:$ & London \\
\hline \hline PublisherImprintName & $:$ & BioMed Central \\
\hline \hline
\end{tabular}

\title{
Differing the gas density for NIPSV
}

\begin{tabular}{|l|l|l||}
\hline \multicolumn{2}{|c|}{ ArticleInfo } \\
\hline \hline ArticleID & $:$ & 4185 \\
\hline \hline ArticleDOI & $:$ & $10.1186 /$ ccf-2000-4031 \\
\hline \hline ArticleCitationID & $:$ & 4031 \\
\hline \hline ArticleSequenceNumber & $:$ & 44 \\
\hline \hline ArticleCategory & $:$ & Paper Report \\
\hline \hline ArticleFirstPage & $:$ & 1 \\
\hline \hline ArticleLastPage & $:$ & 3 \\
\hline \hline & & RegistrationDate : 2000-1-14 \\
\hline ArticleHistory & $:$ & OnlineDate \\
\hline \hline ArticleCopyright & $:$ & Current Science Ltd2000-1-14 \\
\hline \hline ArticleGrants & $:$ & \\
\hline \hline ArticleContext & $:$ & 1305422 \\
\hline \hline
\end{tabular}




\section{Keywords}

Chronic obstructive pulmonary disease (COPD), dyspnea, heliox, helium, mechanical ventilation, noninvasive ventilation, pressure support ventilation

\section{Comments}

The crossover design of this study was used well to answer the question setby the authors. One of the authors of the study, who was responsible forsetting up the NIPSV, had an admirable success rate for establishing thepatients on this mode of ventilation. Such success may suggest that thistechnique can be clinically useful but may require a learning curve for thephysicians involved in establishing the individual patient settings for NIPSV.

\section{Introduction}

The rate of intubation in patients with pre-existing chronic obstructive pulmonary disease (COPD) and having acute respiratory failure hasbeen reduced by the use of noninvasive pressure support ventilation (NIPSV)via a facemask. This reduction in intubation rate has been associated with adecrease in mortality and morbidity. However, many patients requireintubation because they develop respiratory muscle fatigue. A helium : oxygenmix may be useful as it reduces density of inspired gas and so the work ofbreathing. It may also be beneficial because a helium : oxygen mix would increasethe likelihood of laminar flow and so reduce the driving pressure needed fora given flow.

\section{Aims}

To assess whether, in decompensated COPD, NIPSV using70:30 helium : oxygen instead of 70:30 air : oxygen reduces dyspnea andimproves ventilatory variables, gas exchange and hemodynamic tolerance.

\section{Methods}


The study was a prospective, randomized, crossover trial involving 19 medical intensive care patients who had severe COPD. These patients wereadmitted for NIPSV and stabilized with air : oxygen NIPSV for less than $24 \mathrm{~h}$ after intensive care unit (ICU) admission. This was to accustom the patients to NIPSV, so thatwhen the trial period began there was no learning curve. The study protocolfollows:1, baseline measurements $2 \mathrm{~h}$ after last use of NIPSV;2, 45 min of NIPSV with air : oxygen or helium : oxygen;3, no ventilation for $45 \mathrm{~min} ; 4,45 \mathrm{~min}$ of NIPSV with air : oxygen or helium : oxygen. The same ventilators were used for all patients, and the settings determinedbefore the study period by the physician in charge of the patients. The samephysician performed all the ventilatory trials. Any patient requiring morethan $30 \%$ inspired oxygen was excluded from the study.

\section{Results}

Of the original 20 patients, one patient was excluded due to lackof technical information. No patient required intubation because of failureof stabilization. Most patients had severe obstructive airways disease, witha forced expiratory volume of less than 1 litre.NIPSV decreased respiratory rate and increased tidal and minute volumes. There was no difference in these variables when the helium : oxygen mix wascompared with the air : oxygen mix. Peak inspiratory flow was higher with helium :oxygen. $\mathrm{PaO}_{2}$ was increased with NIPSV, while gas mixture made no further difference. $\mathrm{PaCO}_{2}$ decreased during NIPSV and was lower with helium : oxygen than withair : oxygen.Both gas mixtures decreased dyspnea, as measured by the Borg scale, but the decrease was greater with helium : oxygen. All but two patients showed improvement indyspnea score with helium : oxygen mix. Heart rate was also reduced withNIPSV by both gas mixtures. Mean arterial pressure was reduced with air :oxygen but not helium : oxygen mix. NIPSV appeared to be well tolerated, asno ventilatory protocol had to be discontinued.

\section{Discussion}

In decompensated COPD patients, NIPSV with helium : oxygenimproved dyspnea and $\mathrm{PaCO}_{2}$ more than air : oxygen mix. The authors felt thatthe use of helium : oxygen with NIPSV may be beneficial to COPD patients andmay reduce the need for intubation.

\section{References}

1. Jolliet P, Tassaux D, Thouret JM, Chevrolet JC: Beneficial effects of helium : oxygen versus air : oxygen noninvasive pressure support in patients with decompensated chronic obstructive pulmonary disease. Crit Care Med. 1999, 27: 2422-2429. 